\title{
Customer Relationship Management in a Public Cloud environment - Key influencing factors for European enterprises
}

\author{
Rainer Schmidt \\ Munich University of Applied \\ Sciences \\ Rainer.Schmidt@hm.edu
}

\author{
Michael Möhring \\ Munich University of Applied \\ Sciences \\ Michael.Moehring@hm.edu
}

\author{
Barbara Keller \\ Munich University of Applied \\ Sciences \\ research@barbara-keller.net
}

\begin{abstract}
Customer Relationship Management is crucial influencing factor for competitiveness in saturated markets. Public cloud-computing services for customerrelationship management provide many benefits. However, their usage in Europe is reluctant. Our research identifies several core and sub-influence factors and reveals how strong they are. Enterprises strive for covering risks in terms of safety and security. Further important influencing factors are functional completeness and integration into the existing environment. Our research provides new knowledge of the use of public cloud services in general and in particular for the use of customer relationship in a public cloud environment.
\end{abstract}

\section{Introduction}

Saturated markets and substitutable products and services require for new business strategies [1]. In recent times, many enterprises respond by focussing on their customers and their relationship to them with aim to staying competitive. Consequentially, Customer relationship management becomes a core asset of many enterprises [2] [3]. Customer relationship management (CRM) [1] strives for getting a complete view of the customer by integrating all customer related information [4]. At the same time, all communication and actions towards the customer are coordinated and provide a consistent view to the customer. Customer relationship management aims for presenting only one (virtual) face to the customer [4]. The final goal is to increase revenue and profit by a continuously improvement of the relationship with regards to the individual preferences of the single customer.

Customer Relationship Management [5] is of paramount importance for enterprises to stay competitive in saturated markets. It enables enterprises to collect systematically data about customers during the whole customer lifecycle [6] and thus provides the foundation for advanced analytics tools such as predictive and prescriptive analytics. In this way, customer relationship management provides necessary means for individual customer-related decision-making [7].

To improve the quality of decision-making, it is necessary to integrate as many data sources as possible [8]. Unfortunately, many interesting data sources are located outside the protected environment of enterprises. As examples for this purposes, data from mobile apps, reports from salespersons [9], and data collected by connected products [10], also known as the so called internet of things can be mentioned. Enterprises are forced to provide access to internal systems, to tap these resources advantageous. However, this may create a lot of security hassles, because internal systems have to be open to external entities, systems as well as third parties.

In order to avoid penetrating the security layers, enterprises are evaluating alternatives such as using Customer Relationship Management Systems hosted in a public cloud [11]. A public cloud [11] can be defined as a cloud infrastructure provided by a provider selling cloud services [11]. However, contrarily to private cloud solutions this infrastructure is available to general public and can be used by every client of the service provider. Public cloud services offer a number of benefits [11]. They are available with a minimum of forefront investments and without larger lead times. Public cloud services are available ubiquitously and are billed by consumption. Furthermore, the have a high elasticity and scalability in case of increasing demand and thus, implement the vision of utility computing [12].

Inspite of the advantages, enterprises in Europe are very reluctant to use public cloud offerings [13]. Prior, investigations show that European users adopt CRM in a public cloud very slowly [14] [3]. One possible reason is seen in the fact that using public cloud services for providing CRM implies giving crucial data into the hand of third parties [15]. Another possible influencing factor can be found in a high awareness on data security [16]. 
Many enterprises are afraid of that the cloud-service provider may access confidential data due to legal requirements. A further issue are the significantly higher regulatory impediments in the European Union [17], [18], [19].

Between the priorities of the advantanges and risks of CRM in a public cloud environment the must to adopt new technologies for improving business is inevitable. European enterprises are no exception in this progress. However, there exists a necessity for research on the willingness of European enterprises to use CRM in a public cloud environment due to their special demands. In this context, at first, it is important to capture the influencing factors in detail. Subsequently, the investigation how strong these single factors are to support the decision-making and adoption. In particular, this context leads us to our research question: Which are the factors influencing the European users using CRM provided in a public cloud environment and how strong are these factors?

In order to provide the answer we first introduce the background of our research more detailed. In the following section the research design, methods, and data collection are described. The results of our investigations are elaborated thoroughly in section four. Finally, a conclusion of the findings and an outlook for the managerials well as siencentifical contribution is given.

\section{Background}

We collected recent literature based on a systematic literature review according to Cooper [20] in databases such as IEEExplore, AISeL, SpringerLink, ScienceDirect, ACM digital library of the last fifteen years. Therefore, we used related keywords like "Public Cloud" AND "CRM" XOR "Customer Relationship Management". We found sparse research on the investigation for the use of Customer relationship management in a public cloud environment. We set this timeframe with regards to the occurrences of cloud technology and the refreshed awareness of the customer. In our systematic literature review, we found some prior research and interesting results referring to our research question. Some aspects of cost considerations in general for transactional information systems like ERP or CRM as well as SaaS as a possibility for CRM systems are described e.g. in Motahari-Nezhad et al. [21]. These show the possibility of cloud computing for outsourcing business applications like CRM, HR, etc. Furthermore, security aspects are discussed in detail [15] [22]. Liang [23] sketched basically a customer relationship management based on public cloud services

A conceptual model for Customer relationship management in the banking industry based on cloud computing is developed by Hajmaleki and Hashemi [24]. Performance improvements of Organizations by integrating cloud-computing and CRM are discussed by Alryalat et al. [25]. A more general investigation of the merits of CRM in cloud-computing gives Chuang et al. [26]. The benefits of cloud-based CRM-Systems for SMEs are discussed by Gupta [27].

Beside these insights about the cloud, its advantages, and risks as well as its possibilities and challenges, there is a sparse research focussing on the aspects of using CRM in the public cloud. To put it on plainly, there exist no big picture about detailed factors influencing the enterprises' decisions to use CRM in a public cloud environment. Although, cloud computing generally is a fascinating research topic for the last recent years [22], there is only one research article, which fits very well to our research question and can be seta basement for our target to identify the influencing factors detailed and with their individual impacts. Haerting et al [3] made an empirical evaluation of different core influencing factors of the use of CRM in a public cloud environment (Figure 1) based on a qualitative study of European key users. These factors are marketing organization, safety and security, functionality, cost, scalability, integration and one moderator compliance [3].

The marketing organization develops as well as realizes different strategies in relation to promoting, establishing and adjusting the customer, product or service interaction of the enterprise [28] [3]. According to Haerting et al. [3] this is a "very crucial influencing factor". Furthermore, safety and security are influencing factors, which focuses on the awareness of avoidance of hazards such as challenges related to data protection, integrity, authenticity and confidentiality of information

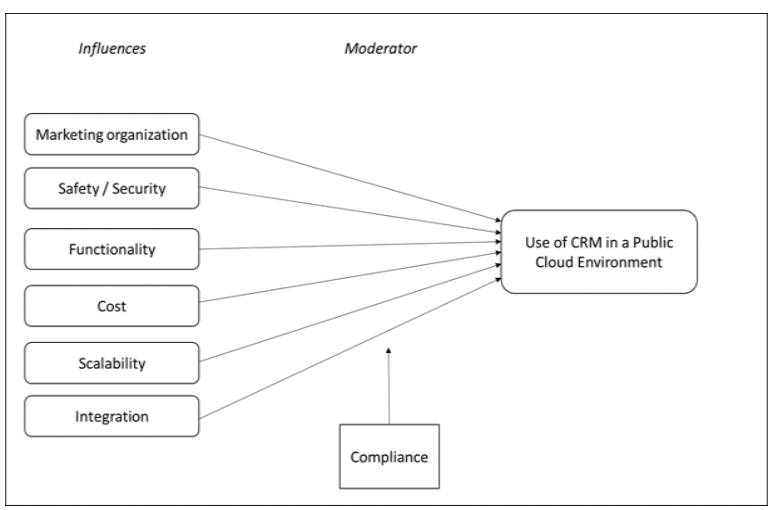

Figure 1: Public Cloud CRM Model based on $[3$, p. 4]

[29] [30] [3]. General aspects of safety and security can be found in [2]. The third influencing factor in this 
model is the functionality. The functionality describes that the CRM system can fulfill different requirements. If the system cannot fulfill all of the needed functions (e.g. for special customer management or reporting) [31] [3], the CRM system in the public cloud is not a good choice. Cost aspects are very often discussed [32] and build a further influencing factor in the model. That means, that public cloud computing can save some costs like fixed costs or better possibilities of writing-off [3]. Another important advantage of cloud computing mentioned in the model is the scalability [32] [33].

Scalability, describes the capability of a system to adjust the IT service demand in relation to the real business demand [34] [3]. Therefore, CRM users can be added or deleted at real time. The final influencing factor of this model is integration. Integration means in this context [3], that the public cloud CRM system must be integrated into the existing enterprise architecture like ERP and e-commerce systems. If the CRM cannot be easily integrated, there might be a lack of data, processes, and functions [35]. Therefore, the use of such a CRM system is not beneficial. In addition to this six influencing factors, there was one factor found which is moderating all of the influencing factors: compliance. Compliance aspects can change the strength of the impacts of all elaborated influencing factors in the model according to Härting et al. [3]. Therefore, due to the compliance regulations of a business sector, the impact of each influencing factor can be strengthened or weaken. For instance, for an enterprise located in a pharmacy environment, the impacts of functionality, cost, safety \& security aspects on the decision to use a CRM in the public cloud environment can be totally different than in the fashion retail sector.

Although the presented research provides some insights into the use of CRM in a public cloud environment in Europe, there are different challenges and questions not addressed so far. First of all, within the model only core influencing factors are covered. Therefore, the question arises, what are the different sub-factors behind this core influencing factors. For instance, marketing organization is a very abstract term, which can be split up in many different directions. It is important to know what can be understood in detail of this factor and of which sub-factors the marketing organization consists. Second, there are no approach or results about how strong the impacts of the elaborated core influencing factors are. However, this point could be very interesting. One the one hand, it could be support the decision making of enterprises thinking about the implementation of using a CRM in the public cloud environment. On the other hand, it could provide suppliers further insights into the requirements of potential customers. Additionally, we want to provide scientifically insights into the use and adoption of cloud computing with the aim to broaden relevant insights in current research, particularly in the field of CRM.

We contribute in our research to the sub-factors and strength of the impact factors. Therefore, we deal with the two main challenges of the model in order to get a better understanding of the use of CRM in a public cloud environment. Haerting et al. also motivate further developments of the model based on these aspects [3].

\section{Research design, methods and data collection}

We implement expert studies based on the approach of a Delphi study, to discover different sub-influencing factors and their impacts of the use of CRM in a public cloud CRM. This method is often used in IS research (e.g. [36] [37] [38] ) to get insights in research field without knowing all dependencies and characteristics before.

Delphi study was originated by a California think tank in early 1950 by utilizes expert knowledge for forecasting or for evaluation [38] [39]. In our approach, we adopted and used the Delphi method to evaluate and get deeper insights into the different influencing factors of the use of CRM in a public cloud environment. In multiple rounds, the experts alter their opinions anonymous and in general based on the feedback of the prior rounds [38].

We selected the experts based on their knowledge [38] in the area of CRM. We contact formally and informally many CRM experts of different European enterprises. The experts were first asked about their different knowledge and background in this field to ensure a high quality of research. Experts were only selected if they have the needed knowledge, background and expertise in the field of CRM in the public Cloud. Finally, we selected about $\mathrm{N}=36$ experts. According to general recommendations [38] [60] this sample size is huge enough to the representativeness of the findings. Our experts have a CRM experience of 10.14 years on average. All experts work in leading positions in their enterprise and wish to remain anonymous. The experts are responsible as well as key managers in this CRM area. The headquarters of the enterprises are mostly located in central European countries like Germany, Austria, Switzerland or in the Netherlands. The enterprises operate in whole Europe with subsidiaries in different states of the European Union with almost the same CRM implementation and strategy. In general, the 
annual turnovers of the enterprises are in a more digit million-euro range.

According to general recommendations [36] [40], we implemented three rounds of the expert study. All items asked for kept during the rounds if the majority of experts selected these items according to general guidelines [6] [41]. The experts being anonymous in each round. In the first round, we asked in a qualitative way which are the detailed sub-factors of each core influencing factor [3]. The qualitative study was implemented through a web-based online survey tool. In the questionnaire of the survey only open questions were asked to get insights about the influencing factors. Besides, we captured the expertise and knowledge of the participants. Afterward, we analyzed the data based on coding techniques according to Strauss and Corbin [42] and prepared the results for the second round. In the second round, the experts evaluate the results of the first round based on the importance of each (sub-) factor for the use of public cloud CRM. Therefore, the importance of each (sub-) factor was evaluated. The quantitative evaluation in this second round based on a 1 to 5 Likert scale [43] (1: very unimportant, 2: unimportant; 3: neither important or unimportant, 4: important; 5: very important). This round was also implemented through a web-based online survey tool. The access to this private survey was sent via email directly to the interviewees. Then, we analyzed the data by using recommended statistical methods [38] and prepared the results for the last round. Therefore, we had to calculate, extract and visualize the results for each sub and core factor based on the individual estimations of our experts. During the third and final round, the experts have seen the final results and make comments if something is not right or some important things have to be noted.

During the rounds, qualitative data and quantitative data were collected. For the analysis of qualitative data, we followed coding techniques like open and selective coding according to Strauss and Corbin [42]. To analyze quantitative data, we used standard deviation, averages/means, etc. like recommended in literature [38]. The experts were contacted in 2015. The different rounds were implemented from November 2015 until May 2016.

The results of the collected data during the rounds will be described in the following section.

\section{Results}

In this section, we describe the results of our expert study round by round. After collecting our expert panel, the first round was implemented based on our research design:

\section{Round 1}

In the first round, we analysed the gathered qualitative data by using open and selective coding techniques according to Strauss and Corbin [42] In this step we collected, defined as well as evaluated more than 40 codes. We only address the important codes mentioned by the maturity of the experts. Based on our analysis we got the following sub-influencing factors for the core influencing factors:

Table 1: Sub-influencing factors

\begin{tabular}{|c|c|}
\hline $\begin{array}{l}\text { Core } \\
\text { influencing factor }\end{array}$ & Sub-factors \\
\hline $\begin{array}{l}\text { Marketing } \\
\text { organization }\end{array}$ & $\begin{array}{l}\text { - Sales processes and } \\
\text { organizational structure } \\
\text { - Corporate collaboration } \\
\text { - Marketing knowledge and } \\
\text { usability } \\
\text { - Currentness and availability } \\
\text { of data } \\
\end{array}$ \\
\hline $\begin{array}{l}\text { Safety \& } \\
\text { Securtity }\end{array}$ & $\begin{array}{l}\text { - Place of the headquarter of } \\
\text { the cloud provider } \\
\text { - Encryption aspects } \\
\text { - Managing different access } \\
\text { rights } \\
\text { - Data privacy } \\
\text { - Trustworthy of the cloud } \\
\text { provider } \\
\text { - Increased safety } \\
\text { - Consideration of EU data } \\
\text { protection laws }\end{array}$ \\
\hline Functionality & $\begin{array}{l}\text { - Customer management } \\
\text { functions } \\
\text { - Forecasting functions } \\
\text { - Reporting functions } \\
\text { - Offline availability and } \\
\text { ubiquitary access function }\end{array}$ \\
\hline Cost & $\begin{array}{l}\text { - Service costs } \\
\text { - Cost of infrastructure } \\
\text { - Saving of costs through the } \\
\text { use of cloud computing }\end{array}$ \\
\hline Scalability & $\begin{array}{l}\text { - Amount of users } \\
\text { - Scalability of each sub } \\
\text { functions of the public cloud } \\
\text { crm solution }\end{array}$ \\
\hline Integration & $\begin{array}{l}\text { - Integration in consistent it } \\
\text { infrastructure }\end{array}$ \\
\hline
\end{tabular}




\begin{tabular}{|l|l|}
\hline & $\begin{array}{l}\bullet \text { Consistent with enterprise } \\
\text { strategy }\end{array}$ \\
\hline $\begin{array}{l}\text { Compliance } \\
\text { (Moderator) }\end{array}$ & $\begin{array}{l}\bullet \text { Internal regulations and laws } \\
\bullet \text { Industry sector specific } \\
\text { aspects }\end{array}$ \\
\hline
\end{tabular}

Through the lens of our experts the marketing organization has four different sub influencing factors. It is important that the public cloud CRM solutions can cover the implemented sales processes and structure. If this is not possible, its use is not possible without huge organizational problems. CRM in a public cloud is very good for implementing a better collaboration through the whole organization [44]. Therefore, corporate collaboration [21] is another sub influencing factor. Furthermore, subfactor three (Marketing knowledge and usability) is also important for an integrated and simple use of the solutions. Factor four explains that the currentness and availability of data [32] is important. Otherwise, customer interactions will be failed based on an incorrect order history, etc. One of our experts of a leading European enterprise argues like that:

$$
\begin{aligned}
& \text { "sales persons must be focused on sales } \\
& \text { conversions." }
\end{aligned}
$$

Safety and security functions were often mentioned by our experts. Core influencing factors in the category are the locationplace of the headquarter of the cloud provider that influences the laws applicable, encryption aspects, the management of different access rights, aspects of data privacy, and the trustworthy of the cloud provider. Also the provider and an increased safety through the use of public cloud computing based on better security knowledge of the cloud provider. Furthermore, the consideration of EU data protection laws was mentioned. One of our experts shows the importance of these sub-factors like:

"safety and security issues are important and are at the top of our list for preparation decisions related to CRM."

Subfunctions of the core category functionality are the following four. First, all needed functions of the customer management like master data management [45][43] must be fulfilled through this new cloud solutions. For a better preparation for the future, the forecasting functionality is crucial according to our experts. It can also be used for prevention customer churn [46][34]. Reporting as a third sub factory is also very crucial. Detailed reports of e.g. customer interactions and sales indicators are possible and essential for the marketing and sales department [47] [48][10] [36]. Furthermore, if the sales staff is outside of the enterprise, they need access to the data maybe an offline availability and ubiquitous access function.

Cost aspects are very fundamental according to Härting et al. [3]. Our experts show different interesting insights in this influencing factor. First of all, service costs for support, or education are essential for using a public cloud CRM system. Furthermore, experts argue, that the cost of the internal infrastructure like a computer and internet access must be considered as a further subfactor. According to general discussion of cloud computing costs [32], our experts think that costs saving by implementing CRM in a public cloud are a further important subfactor in this category.

The scalability factor consists of two subfactors according to our experts. The amount of users drives the need for scalability [49]. Furthermore, if the cloud solution differentiated between different parts for scaling like data processing, user access, etc. there is a need to observe all aspects of parts for scalability.

Aspects of the integration were viewed by our experts into two sub influencing factors. The integration should 1) cover and connect to all relevant information systems through integration of e.g. data, processes, functions [35] [50], and 2) integrate all aspects of the enterprise strategy. Therefore, aspects of business IT alignment [51] and strategic alignment [50] should be considered.

Finally, the first round also discovers the moderator compliance. The experts argue that internal regulations and general laws are one sub influencing factor. Furthermore, industry specific aspects are the second sub-factor. For instance, if an enterprise operates in the pharmacy sector, there are other regulations as in the manufacturing sector [52][6].

\section{Round 2}

For evaluation of the results of round 1, the experts get the pre-processed results for evaluation. The results are summarized in Table 2 as well as described in the following. According to the research methods section, the experts evaluate the different influencing factors based on a Likert scale from 1 (very unimportant) to 5 (very important). Furthermore, significance tests of the mean for each factor were made to ensure a high quality of research. 


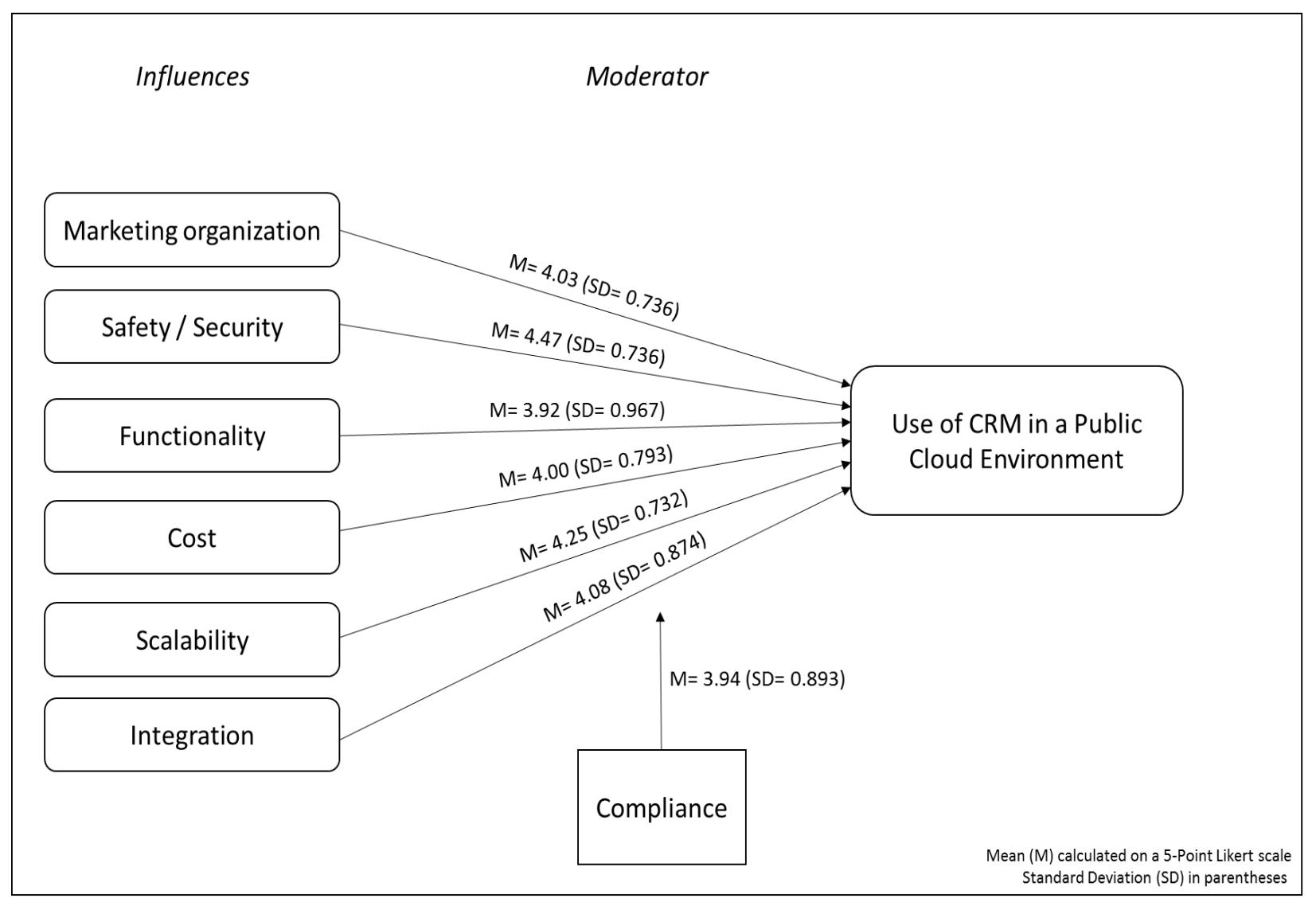

Figure 2: Public Cloud CRM Core Influencing Factors

First, an evaluation of a compromised view of the core influencing factors showed the following results:

Table 2: Core Influencing Factors

\begin{tabular}{|l|c|c|}
\hline $\begin{array}{l}\text { Core } \\
\text { influencing factor }\end{array}$ & Mean & $\begin{array}{c}\text { Standard } \\
\text { Deviation }\end{array}$ \\
\hline Marketing organization & 4.03 & 0.736 \\
\hline Safety \& Security & 4.47 & 0.736 \\
\hline Functionality & 3.92 & 0.967 \\
\hline Cost & 4.00 & 0.793 \\
\hline Scalability & 4.25 & 0.732 \\
\hline Integration & 4.08 & 0.874 \\
\hline $\begin{array}{l}\text { Compliance } \\
\text { (Moderator) }\end{array}$ & 3.94 & 0.893 \\
\hline
\end{tabular}

According to table Table 2 all core influencing factors are important, because of an average evaluation value above 3.00, the mean of the used Likert scale. In fact, this means that all of the evaluated factors are neither neutral or unimportant. Therefore, all collected core factors are important as well as relevant due to the research question.

Safety and security aspects are the most important influencing core factor. This can be explained because of the special situation and environment of the European Union, as mentioned before. Scalability is the second important influencing factor. One of the most important properties of cloud computing address scalability. Therefore, scalability is also very interesting for the use of CRM in the public cloud.

The other core factors are in a similar range of importance. Managers may think in a more or less equal way for preparing a decision through CRM in a public cloud environment.

Second, a deeper look into the sub influencing factors shows the results listed in table 3 . 
Table 3: Sub-influencing factors

\begin{tabular}{|c|c|c|}
\hline $\begin{array}{l}\text { Core } \\
\text { influencing } \\
\text { factor }\end{array}$ & Sub-factors & $\begin{array}{c}\text { Mean } \\
\text { (Standard } \\
\text { Deviation) } \\
\end{array}$ \\
\hline \multirow[t]{4}{*}{$\begin{array}{l}\text { Marketing } \\
\text { organization }\end{array}$} & $\begin{array}{l}\text { - Sales processes and } \\
\text { organizational } \\
\text { structure }\end{array}$ & $\begin{array}{c}4.31 \\
(0.786)\end{array}$ \\
\hline & $\begin{array}{l}\text { - Corporate } \\
\text { collaboration }\end{array}$ & $\begin{array}{c}4.00 \\
(0.894)\end{array}$ \\
\hline & $\begin{array}{l}\text { - Marketing knowledge } \\
\text { and usability }\end{array}$ & $\begin{array}{c}4.64 \\
(0.692) \\
\end{array}$ \\
\hline & $\begin{array}{l}\text { - Currentness and } \\
\text { availability of data }\end{array}$ & $\begin{array}{c}4.58 \\
(0.692)\end{array}$ \\
\hline \multirow[t]{7}{*}{$\begin{array}{l}\text { Safety \& } \\
\text { Security }\end{array}$} & $\begin{array}{l}\text { Place of the } \\
\text { headquarter of the } \\
\text { cloud provider }\end{array}$ & $\begin{array}{c}4.36 \\
(0.833)\end{array}$ \\
\hline & - Encryption aspects & $\begin{array}{c}4.47 \\
(0.774) \\
\end{array}$ \\
\hline & $\begin{array}{l}\text { - Managing different } \\
\text { access rights }\end{array}$ & $\begin{array}{c}4.56 \\
(0.695) \\
\end{array}$ \\
\hline & - Data privacy & $\begin{array}{c}4.67 \\
(0.717) \\
\end{array}$ \\
\hline & $\begin{array}{l}\text { - Trustworthy of the } \\
\text { cloud provider }\end{array}$ & $\begin{array}{c}4.83 \\
(0.561) \\
\end{array}$ \\
\hline & - Increased safety & $\begin{array}{c}4.14 \\
(0.961)\end{array}$ \\
\hline & $\begin{array}{l}\text { - Consideration of EU } \\
\text { data protection laws }\end{array}$ & $\begin{array}{c}4.53 \\
(0.774) \\
\end{array}$ \\
\hline \multirow[t]{4}{*}{ Functionality } & $\begin{array}{l}\text { - Customer management } \\
\text { functions }\end{array}$ & $\begin{array}{c}4.28 \\
(0.741)\end{array}$ \\
\hline & - Forecasting functions & $\begin{array}{c}3.78 \\
(0.929) \\
\end{array}$ \\
\hline & - Reporting functions & $\begin{array}{c}4.17 \\
(1.028)\end{array}$ \\
\hline & $\begin{array}{l}\text { - Offline availability and } \\
\text { ubiquitary access } \\
\text { function }\end{array}$ & $\begin{array}{c}4.17 \\
(0.775)\end{array}$ \\
\hline \multirow[t]{3}{*}{ Cost } & - Service costs & $\begin{array}{c}3.97 \\
(0.910)\end{array}$ \\
\hline & - Cost of infrastructure & $\begin{array}{c}3.44 \\
(1.206) \\
\end{array}$ \\
\hline & $\begin{array}{l}\text { - Saving of costs } \\
\text { through the use of } \\
\text { cloud computing }\end{array}$ & $\begin{array}{c}4.17 \\
(0.971)\end{array}$ \\
\hline \multirow[t]{2}{*}{ Scalability } & - Amount of users & $\begin{array}{c}3.58 \\
(0.967)\end{array}$ \\
\hline & $\begin{array}{l}\text { - Scalability of each } \\
\text { sub-function of the }\end{array}$ & $\begin{array}{c}4.08 \\
(0.874)\end{array}$ \\
\hline
\end{tabular}

\begin{tabular}{|c|c|c|}
\hline & $\begin{array}{l}\text { public cloud CRM } \\
\text { solution }\end{array}$ & \\
\hline \multirow[t]{2}{*}{ Integration } & $\begin{array}{l}\text { - Integration in } \\
\text { consistent IT } \\
\text { infrastructure }\end{array}$ & $\begin{array}{c}3.94 \\
(1.068)\end{array}$ \\
\hline & $\begin{array}{l}\text { - Consistent with } \\
\text { enterprise strategy }\end{array}$ & $\begin{array}{c}4.00 \\
(1.042) \\
\end{array}$ \\
\hline \multirow[t]{2}{*}{$\begin{array}{l}\text { Compliance } \\
\text { (Moderator) }\end{array}$} & $\begin{array}{l}\text { - Internal regulations } \\
\text { and laws }\end{array}$ & $\begin{array}{c}3.97 \\
(0.736)\end{array}$ \\
\hline & $\begin{array}{l}\text { - Industry sector specific } \\
\text { aspects }\end{array}$ & $\begin{array}{c}3.56 \\
(0.810)\end{array}$ \\
\hline
\end{tabular}

Through the lens of our experts some sub influencing factors are more important than others. For instance, the trustworthiness of the cloud provider is nearly very important (average: 4.83). It can be explained, that the managers will choose a good provider to reduce risks and costs in terms of e.g. switching costs according to risk [53] [54] and transaction cost theory [55]. Some sub influencing factors like the cost of the infrastructure (average: 3.44) seems to be not so high important like the other factors. However, all founded factors of the first round are important and evaluated through this second round. Furthermore, the standard deviation is in a satisfying range according to general standards.

Furthermore, the use of Customer Relationship Management in a public cloud environment is important for our experts (average: 3.86; standard deviation: $0.639)$.

To ensure a high quality of research, we tested the significance of the values through a one-side t-test [56]. For testing the means of each influence factor, we used as reference value: 1 (very unimportant), 2 (unimportant), 3 (neither) (according to the Likert scale of the question). We got a significance about $\mathrm{p}<0.05$ for each value. Therefore, we ensure that all (sub-) factors are important. Consequently, each impact factor is significant more important as unimportant. This testing is also often used in research [56] [57].

\section{Round 3}

The target of round 3 was to discuss the final results with the experts to ensure a high quality of research. All experts agree with the results. Therefore, we finished our expert study within three rounds. One expert of a well-established enterprise argues like that:

"The results are in accordance with the expectations." 
Furthermore, in addition to these three round expert study we secondly evaluate our final results with other CRM key account users of eleven different European enterprises in a webinar session in May 2016. The experts have ca. 5 years of working experience in the CRM field on average. Consistent with the evaluation of our results with the main experts in our study, these experts agree with our results.

\section{Conclusion and discussion}

Customer relationship management is a very important and challenging topic for enterprises and organizations. The ubiquitous access to all relevant customer data can be a favourable advantage for enterprises in terms of staying competitive. Therefore, using a CRM in a public Cloud environment can be very helpful. In contrast to other well-adopting countries like the US, European users slowly adopt CRM in a public cloud [14] [3]. We discovered different interesting influence factors, consistent and extending with prior research [3]. Besides, we found out how strong the influencing factors impact is and which sub-factors are important related to the core influencing factors. For instance, we show that safety and security aspects are the most important influencing factors for users to implement a CRM information system in a public cloud environment. These results are further consistent with risk theory [53] [54]. Similar results were found for all other aspects investigated in our research. All of the other influencing and sub-influencing factors were evaluated by the statistics methods as important, too. We can derive from the results, that enterprises should cover risks in terms of safety and security - e.g. where the CRM is hosted and the data is stored. Furthermore, it is important to provide the important functions and integrate the system into the existing environment as well as marketing organizational aspects. These results can be explained based on the use of utility theory [58]. Our research contributes to the current information systems literature by adding this new knowledge of the use of public cloud services in general and in particular for the use of customer relationship management in a public cloud environment. We have further developed the model of Haerting et al. [3]. Academics can use these results to adopt and further develop current approaches of cloud computing and special aspect of customer relationship management. Practical users can benefit from our results, for a better evaluation of the use of CRM in the public cloud. Furthermore, decisions can be better prepared based on our different discovered influencing factors.
Limitations can be found in the used methodology [38]. For instance, the transfer of the Cloud CRM experts' opinions on to the managements' viewpoint can be rough hard. Furthermore, experts can be biased [59] by their involvement into the topic. However, the methodology is often used in IS research (e.g. [37] [38] [39]). Hence, the chosen approach and the elaborated results have a high quality and can be seen as a valid. Furthermore, the specific evaluation of the European market has to be respected. Future research should take into account these limitations and compare different markets and key users of public cloud CRM (e.g. Europe and US, Europe and BRIC states). Furthermore, the separate investigation of different IT projects would be a good starting point for future research. In this context, the performance should be measured in a pre-post comparison.

Acknowledgement: We thank Markus Heinrich, Marcel Sprenger, Andreas Weiß, Kuppler Andreas, Sabrina Loth, Marion Schwenger, Björn Köpf, Daniel Hompf, Marcel Emert, Christoph Stöcker, Tobias Arnold, Marc Grieser, Dennis Gölz, Kilian Erkert, Kin Wasili, Jan Stierhof, Oliver Kollmar, Andreas Maier, Johannes Otter, Mathias Motzer, Martina Häußler as well as our experts and the other facilitators for supporting our research.

\section{References}

[1] Payne, A. and Frow, P. "A strategic framework for customer relationship management". Journal of Marketing, vol. 69, no. 4, 2005, pp. 167-176.

[2] Leveson, N.G. "Software safety: Why, what, and how". ACM Computing Surveys (CSUR), vol. 18, no. 2, 1986, pp. 125-163.

[3] Härting, Ralf-Christian, Möhring, M., Schmidt, R., Reichstein, C., and Keller, B. "What drives users to use CRM in a Public Cloud environment? - Insights from European Experts". Proceedings of the 49th Hawaii International Conference on System Sciences (HICSS), Kauai, IEEE, 2016, pp. 3999-4008.

[4] Kumar, V. and Reinartz, W. "Customer Relationship Management: Concept, Strategy, and Tools”. Springer, New York, 2012.

[5] Gosney, J.W. and Boehm, T.P. "Customer relationship management essentials". Prima Communications, 2000.

[6] Jain, D. and Singh, S.S. "Customer lifetime value research in marketing: A review and future directions". Journal of Interactive Marketing, vol. 16, no. 2, 2002, pp. 34-46.

[7] Putler, D.S. and Krider, R.E. "Customer and business analytics: Applied data mining for business 
decision making using R". Chapman \& Hall/CRC, 2012.

[8] Davenport, T.H. and Harris, J.G. "Competing on Analytics: The New Science of Winning Harvard Business School Press". Harvard Business Press, 2007. [9] Benni, E., Hjartar, K., and Laartz, J. "The IT factor in mobile services - McKinsey Quarterly - Operations Product Development". McKinsey Quarterly, 2003, pp. 87-93.

[10] Porter, M.E. and Heppelmann, J.E. "How Smart, Connected Products Are Transforming Companies". Harvard Business Review. vol. 93, no. 10, 2015, pp. 96114.

[11] Mell, P. and Grance, T. "The NIST Definition of Cloud Computing". 2009. http://tinyurl.com/lovlvh.

[12] Ivanov, I.I. "Utility Computing: Reality and Beyond". In E-business and Telecommunications. 2009, pp. 16-29.

[13] FAZ. "Deutsche Unternehmen halten sich von der Cloud fern. Frankfurter Allgemeine Zeitung”. 2014. http://tinyurl.com/qzk3ubq.

[14] Eurostat. "Use of cloud computing services", 2014. http://tinyurl.com/zteytc4.

[15] AlZain, M., Pardede, E., Soh, B., Thom, J., and others. "Cloud computing security: from single to multiclouds"., 45th Hawaii International Conference on System Science (HICSS), IEEE, 2012, pp. 5490-5499.

[16] Etro, F. "The economic impact of cloud computing on business creation, employment and output in Europe". May, 2009.

[17] Directive, E.U. EU Data Protection Directive. 1995.

[18] Fischl, T. and Weimer, K.A. "Cloud Computing A German Perspective”. 2014 .http://tinyurl.com/zr2j5y3.

[19] Doelitzscher, F., Reich, C., and Sulistio, A. "Designing cloud services adhering to government privacy laws". IEEE 10th International Conference on Computer and Information Technology (CIT), IEEE, 2010, pp. 930-935.

[20] Cooper, H.M. "Synthesizing research: A guide for literature reviews". Sage, 1998.

[21] Motahari-Nezhad, H.R., Stephenson, B., and Singhal, S. „Outsourcing Business to Cloud Computing Services: Opportunities and Challenges“. IEEE Internet Computing. 2009, pp. 1-11.

[22] Zhang, Q., Cheng, L., and Boutaba, R. "Cloud computing: state-of-the-art and research challenges". Journal of Internet Services and Applications, vol. 1, no. 1, 2010, pp. 7-18.

[23] Liang, X. "CRM Business Cloud Computing". Proceedings of the 2011 International Conference on Innovative Computing and Cloud Computing, ACM, 2011, pp. 103-106.
[24] Hajmaleki, F. and Hashemi, S.M. "Designing Conceptual Model for Banking Customer Relationship Management Systems Based on Cloud Computing”. International Journal of Engineering Research and Technology, vol. 3, no. 8, 2014, pp. 934-938.

[25] Alryalat, H., Alhawari, S. "Integration between Cloud Computing Benefits and Customer Relationship Management (CRM) Processes to Improve Organization's Performance". International Journal of Cloud Applications and Computing (IJCAC), vol. 4, no. 1, 2014, pp. 1-14.

[26] Chuang, H.-M., Lin, C.-K., Chen, D.-R., Chen, Y.S., and Wang, L.-C. "Elucidating the Merits of Customer Relationship Management in Cloud Computing". Applied Mathematics \& Information Sciences, vol. 9, no. 4 , 2015, pp. 2001-2013.

[27] Gupta, P. "Customer relationship management systems for the SME's-is this a perfect marriage made in the cloud?", 2014. http://tinyurl.com/j2kkwlp.

[28] Kotler, P. and Armstrong, G. "Principles of Marketing". Pearson Education, 2010.

[29] Banerjee, A., Venkatasubramanian, K.K., Mukherjee, T., and Gupta, S.K.S. "Ensuring safety",, Proceedings of the IEEE security, and sustainability of mission-critical cyber-physical systems, 2012, pp. 283299.

[30] Commission, I.E. and others. „IEC 60601-1: 2005 Medical electrical equipment-Part 1: General requirement for basic safety and essential performance". Geneva, 2005.

[31] Len, B., Paul, C., and Rick, K. "Software architecture in practice". Boston, Massachusetts Addison, 2003.

[32] Armbrust, M., Fox, A., Griffith, R. "A view of cloud computing”. Commun. ACM, vol. 53, no. 4, 2010, pp. 50-58.

[33] Furht, B. "Cloud Computing Fundamentals". In B. Furht and A. Escalante, eds., Handbook of Cloud Computing. Springer US, Boston, MA, 2010, pp. 3-19. [34] Herbst, N.R., Kounev, S., and Reussner, R. "Elasticity in Cloud Computing: What It Is, and What It Is Not". ICAC, 2013, pp. 23-27.

[35] Scheer, A.W. "ARIS-business process modeling". Springer Verlag, 2000.

[36] Brancheau, J.C., Janz, B.D., and Wetherbe, J.C. "Key issues in information systems management: 199495 SIM Delphi results". MIS Quarterly, 1996, vol. 11, no. 1, pp. 225-242.

[37] Akkermans, H.A., Bogerd, P., Yücesan, E., and Van Wassenhove, L.N. "The impact of ERP on supply chain management: Exploratory findings from a European Delphi study". European Journal of Operational Research, vol. 146, no. 2, 2003, pp. 284301. 
[38] Worrell, J.L., Di Gangi, P.M., and Bush, A.A. "Exploring the use of the Delphi method in accounting information systems research". International Journal of Accounting Information Systems, vol. 14, no. 3 , 2013, pp. 193-208.

[39] Dalkey, N. and Helmer, O. "An experimental application of the Delphi method to the use of experts". Management Science, vol. 9, no. 3, 1963, pp. 458-467. [40] Okoli, C. and Pawlowski, S.D. "The Delphi method as a research tool: an example, design considerations and applications". Information \& Management, vol. 42, no. 1 , 2004, 15-29.

[41] Schmidt, R.C. "Managing Delphi surveys using nonparametric statistical techniques". Decision Sciences, vol. 28, no. 3 ,1997, pp. 763-774.

[42] Strauss, A. and Corbin, J. "Open coding. Basics of qualitative research: Grounded theory procedures and techniques 2", 1990, pp. 101-121.

[43] Likert, R. "A technique for the measurement of attitudes". Archives of Psychology, 1932.

[44] O’Brien, J.A. and Marakas, G.M. "Introduction to information systems". McGraw-Hill/Irwin New York City, USA, 2005.

[45] Loshin, D. "Master data management". Morgan Kaufmann, 2010.

[46] Hung, S.-Y., Yen, D.C., and Wang, H.-Y. "Applying data mining to telecom churn management". Expert Systems with Applications, vol. 31, no. 3, 2006, pp. 515-524.

[47] Rygielski, C., Wang, J.-C., and Yen, D.C. "Data mining techniques for customer relationship management". Technology in Society, vol. 24, no. 4, 2002, pp. 483-502.

[48] Chen, I.J. and Popovich, K. "Understanding customer relationship management (CRM) People, process and technology". Business Process Management Journal, vol. 9, no. 5 , 2003, pp. 672-688. [49] Armbrust, M., Fox, A., Griffith, R."Above the clouds: A Berkeley view of cloud computing". EECS Department, University of California, Berkeley, Tech. Rep. UCB/EECS-2009-28, 2009.
[50] Hasselbring, W. "Information system integration". Communications of the ACM, vol. 43, no. 6 , 2000, pp. 32-38.

[51] Loshin, D. "Business intelligence the savvy manager's guide". Morgan Kaufmann, Waltham, MA, 2012.

[52] Kaufman, B. and Novack, G.D. "Compliance issues in manufacturing of drugs". The ocular surface, vol. 1, no. 2 , 2003, pp. 80-85.

[53] Featherman, M.S. and Pavlou, P.A. "Predicting eservices adoption: a perceived risk facets perspective". International Journal of Human-computer Studies, vol. 59, no. 4 , 2003, pp.451-474.

[54] Bauer, R.A. "Consumer behavior as risk taking. Dynamic marketing for a changing world", 398, 1960.

[55] Williamson, O.E. "Transaction-Cost Economics: The Governance of Contractual Relations". Journal of Law and Economics, vol. 22, no. 2, 1979, pp. 233-261. [56] Zimmermann, D.W. and Zumbo, B.D. "Rank transformations and the power of the Student t test and Welch t'test for non-normal populations with unequal variances." Canadian Journal of Experimental Psychology/Revue canadienne de psychologie expérimentale, vol. 47, no. 3, 1993, pp. 523-539.

[57] Schmidt, R., Möhring, M., Maier, S., Pietsch, J., and Härting, R.-C. "Big Data as Strategic Enabler Insights from Central European Enterprises". In W. Abramowicz and A. Kokkinaki, eds., Business Information Systems. Springer International Publishing, 2014, 50-60.

[58] Fishburn, P.C. "Utility theory for decision making". DTIC Document, 1970.

[59] Malsch, M., \& Freckelton, I. "Expert Bias and Partisanship: A Comparison Between Australia and the Netherlands". Psychology, Public Policy, and Law, vol. 11, no. 1, 2005, pp. 42-61.

[60] Skinner, R., Nelson, R. R., Chin, W. W., \& Land, L. „The Delphi method research strategy in studies of information systems". Communications of the AIS, vol. 37, no. 1, 2015, pp. 31-63. 